\title{
FLEXURAL STRENGTH AND MODULUS OF ELASTICITY OF TWO BASE MATERIALS. AN IN VITRO COMPARATIVE STUDY
}

\author{
Sara H. Younis * and Eman Alaa **
}

\begin{abstract}
Objective: To determine and compare flexural strength and modulus of elasticity of two base materials. Materials and Methods: 30 specimens made of the two materials (Activa Bioactive Base and Ionoseal GI Composite Cement) were divided into two groups; 15 specimens in each group, the materials were inserted at a single increment into prefabricated Teflon mold with dimensions of $12 \mathrm{~mm} \times 2 \mathrm{~mm} \times 2 \mathrm{~mm}$ placed on a glass plate according to manufacturer's instructions. Flexural strength and modulus of elasticity were evaluated by a 3 point bending test by using an Instron universal testing machine $(0.75 \mathrm{~mm} / \mathrm{min} \& 0.03 \mathrm{~Hz}$ for hundred cycles). Displacement, Flexural stress and Load were performed for all tests. Then all data were statistically evaluated and compared. Statistical data analysis was performed for flexural fatigue through the least frequent events method. Results: There was no statistically significant difference between mean flexural strength of Activa and Ionoseal $(P$-value $=0.248$, Effect size $=0.679)$. Activa showed statistically significantly lower mean modulus of elasticity than IONA ( $P$-value $=0.015$, Effect size $=1.603$ ). Conclusion: Activa Bioactive-enhanced RMGIs demonstrated comparable flexural strength to Ionoseal glass ionomer composite cement and showed lower modulus of elasticity.
\end{abstract}

KEYWORDS: Flexural strength, Modulus of elasticity, Activa, Ionoseal, Base.

\section{INTRODUCTION}

Conventional glass ionomers, resin modified glass ionomers, flowable resin composites, each provide certain benefits for treatment as a base material. RMGIs have the same ion-releasing glass as filler particles used in conventional GIs, but in small sizes, its initial setting reaction is triggered by light, followed by acid-base reaction after absorption of water. ${ }^{1}$
ACTIVA Bio ACTIVE comprises an enhanced RMGI with a blend of diurethane monomers modified by the insertion of a hydrogenated polybutadiene (a synthetic rubber) and methacrylatebased monomers. The added resin monomers are claimed to improve wear resistance, fracture, and marginal chipping. According to the manufacturers, ACTIVA bioactive products are strong, esthetic,

\footnotetext{
* Lecturer, Department of Conservative Dentistry, Faculty of Oral and Dental Medicine, Future University in Egypt, Cairo, Egypt.

** Lecturer, Department of Pediatric Dentistry and Dental Public Health, Faculty of Oral and Dental Medicine, Future University in Egypt, Cairo, Egypt.
} 
and long-lasting materials that can replace GIs, which are bioactive but have poor esthetics and poor physical properties. Previous studies have shown that ACTIVA products have physical characteristics which closely resemble the strength and wear resistance of composites, although they do not contain bisphenol A or its derivatives. In addition, they can release and recharge with calcium, phosphate and more fluoride than GIs and continuously react to $\mathrm{pH}$ changes in the mouth. They can also form a chemical bond to teeth and seal the cavities against bacterial microleakage. ${ }^{2}$

Ionoseal is a light-curing glass ionomer composite cement for linings, extended fissure sealing and treatment of smaller lesions. ${ }^{3}$

Both materials provide the best attributes of glass ionomers and composite resins. ACTIVA Bio ACTIVE Base/Liner adheres to dentin without etching or bonding, has bioactive fillers, which mimic the physical and chemical properties of natural teeth, and they actively participate in a dynamic system of ion exchange with the saliva and tooth structure. ${ }^{4}$

International Standards Organization (ISO) testing protocol for polymer-based dental restorative materials (ISO 4049, Type 1) utilizes flexural strength as a specified test method for acceptance of polymer-based restorative materials. Flexural strength is the mechanical resistance condition known as a failure caused by the tension of the resin material measured by its curvature. The clinical relevance of this property is present primarily in TABLE (1): Materials used in the current study. the act of mastication, when there are different masticatory forces, which induce various stresses, both in the tooth and the restoration. In addition to the flexural strength, another important parameter supplied by the mechanical flexural test is the modulus of elasticity, which describes the relative stiffness or hardness of a material measured by the reduction in the elastic region of the deformation/ stress diagram. It is the principle of the lower deflection for a given value, the greater is the value of the modulus of elasticity. Its importance is because different clinical situations require a restorative material with different elastic moduli. ${ }^{5}$

Activa Bioactive-Base/Liner is a recently introduced enhanced RMGIs, the manufacturer (Pulpdent Corporation, Watertown, MA) reports that it possesses the properties of a RMGI plus a modified resin matrix with improved resilience and physical properties. ${ }^{2}$

This material may provide enhanced durability and clinical performance and thus should be evaluated regarding its strength properties. Thus the aims of this study were to evaluate and compare; the flexural strength \& modulus of elasticity of Activa enhanced RMGIs and Ionoseal glass ionomer composite cement.

\section{MATERIALS AND METHODS}

\section{Materials}

Materials used in this study are listed in Table 1

\begin{tabular}{|c|c|c|c|}
\hline Materials & Classes & Manufacturers Batches & Compositions \\
\hline $\begin{array}{c}\text { Activa } \\
\text { Bioactive } \\
\text { Base/Liner }\end{array}$ & $\begin{array}{c}\text { (Resin reinforced glass ionomer } \\
\text { cement RMGI) }\end{array}$ & $\begin{array}{l}\text { Pulpdent Corporation, } \\
\text { Watertown, MA USA }\end{array}$ & $\begin{array}{l}\text { - Proprietary mixture of diurethane, other } \\
\text { methacrylates and modified polyacrylic acid } \\
\{53.2 \%\} \text {. } \\
\text { - Amorphous silica }\{3.0 \%\} \text {. } \\
\text { - Sodium fluoride }\{0.90 \%\} \text {. }\end{array}$ \\
\hline Ionoseal & $\begin{array}{l}\text { Light curing glass ionomer } \\
\text { composite liner (Resin reinforced } \\
\text { glass ionomer cement RMGI) }\end{array}$ & $\begin{array}{l}\text { Voco Cuxhaven, } \\
\text { Germany } 1032024\end{array}$ & $\begin{array}{c}\text { Fluoro aluminum silicate, } \\
\text { Bis GMA, HEMA, TEDMA, Champherechinon, } \\
\text { Amine }\end{array}$ \\
\hline
\end{tabular}




\section{Methods}

30 specimens made of the two materials were divided into two groups; 15 specimens in each group, the materials were inserted at a single increment into prefabricated Teflon mold with dimensions of $12 \mathrm{~mm} \times 2 \mathrm{~mm} \times 2 \mathrm{~mm}$ placed on a glass plate. A colorless polyester strip (FAVA, São Paulo, SP, USA) was positioned on the metallic matrix and then pressed by a second glass plate. After the removal of the glass plate, the excess material was removed with the aid of a spatula. Then, the materials were photo-activated through the LED device according to the manufacturer's instructions . Then the specimens were stored in plastic containers in dark for $24 \mathrm{~h}$ at $37^{\circ} \mathrm{C}$. Then, the specimens were subjected to modified flexural test, to determine the values of mini flexural strength and modulus of elasticity. The specimens were placed in a threepoint test device containing two parallel surfaces apart from each other by $9 \mathrm{~mm}$ and subjected to load equidistant to support points, at a rate of 0.75 $\mathrm{mm} / \mathrm{min}$ in a universal testing machine EMIC (DL2000,São Jose dos Pinhais, PR, Brazil).

The results of the flexural strength were obtained in $\mathrm{N}$ and converted to MPa by using the formula from ISO 4049 specification, described below: $\sigma=$ $3 \mathrm{FI} / 2 \mathrm{bh} 2$ Where $\sigma$ is the flexural strength (MPa), $\mathrm{F}$ is maximum load supported $(\mathrm{N}), \mathrm{I}$ is the length between the supporting points $(9 \mathrm{~mm}), \mathrm{b}$ is the width of the prism $(2 \mathrm{~mm})$, and $\mathrm{h}$ is the thickness of the prism $(2 \mathrm{~mm})$. To calculate the elastic modulus following formula was applied: á=I3 x F1 /4fbh3 Where I is the length between the supporting points, $\mathrm{b}[2 \mathrm{~mm}]$ and $\mathrm{h}[2 \mathrm{~mm}]$ are respectively the width and the height of the specimens, F1 $[\mathrm{N}]$ is the load and $\mathrm{f}[\mathrm{mm}]$ is the deflection of the bar (in the elastic phase). The flexural strength and modulus of elasticity values were submitted to two-way ANOVA and turkey test.

\section{Statistical Analysis}

Numerical data were explored for normality by checking the distribution of data and using tests of normality (Kolmogorov-Smirnov and ShapiroWilk tests). Data showed normal (parametric) distribution. Data were presented as mean, standard deviation (SD) and 95\% Confidence Interval for the mean $(95 \% \mathrm{CI})$ values. Student's t-test was used to compare between the two materials. The significance level was set at $\mathrm{P} \leq 0.05$. Statistical analysis was performed with IBM SPSS Statistics for Windows, Version 23.0. Armonk, NY: IBM Corp.

\section{RESULTS}

There was no statistically significant difference between mean flexural strength of Activa and Ionoseal $(P$-value $=0.248$, Effect size $=0.679)$. Activa showed statistically significant lower mean modulus of elasticity than Ionoseal $(P$-value $=$ 0.015 , Effect size $=1.603$ ) as shown in table 2 and figures 1 and 2 .

TABLE (2): Descriptive statistics and results of Student's t-test for comparison between the two materials.

\begin{tabular}{|c|c|c|c|c|c|c|}
\hline \multirow{2}{*}{ Materials } & \multicolumn{2}{|c|}{ Activa } & \multicolumn{2}{|c|}{ Ionoseal } & \multirow{2}{*}{$P$-value } & \multirow{2}{*}{$\begin{array}{c}\text { Effect size } \\
\text { (d) }\end{array}$} \\
\hline & Mean (SD) & $95 \% \mathrm{CI}$ & Mean (SD) & $95 \% \mathrm{CI}$ & & \\
\hline Flexural strength & $117.4(8.8)$ & $108.2-126.7$ & $126.2(15.6)$ & $111.8-140.7$ & 0.248 & 0.679 \\
\hline Modulus of elasticity & $1809(385.3)$ & $1432.7-2185.2$ & $2764.7(738)$ & $2082.2-3447.3$ & $0.015^{*}$ & 1.603 \\
\hline
\end{tabular}

$*$ : Significant at $P \leq 0.05$ 


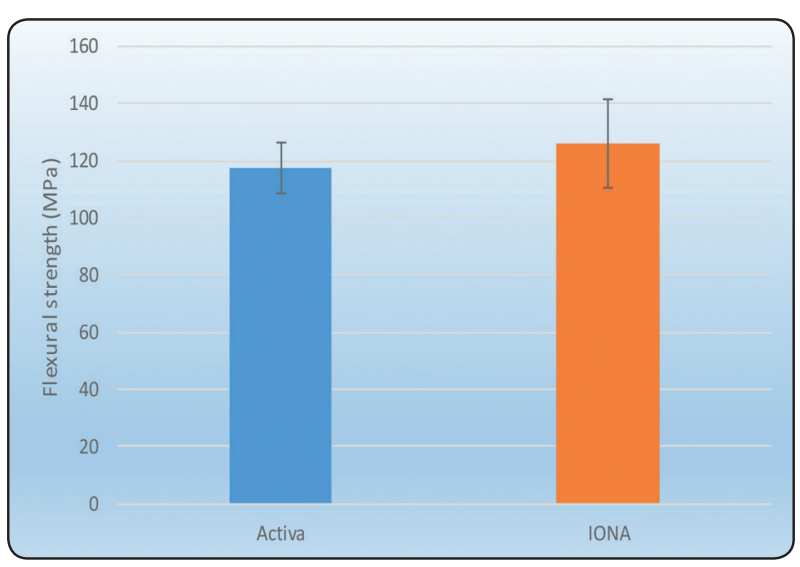

Fig. (1): Bar chart representing mean \& standard deviation values for flexural strengths of the two materials. (Active: blue color \& Ionoseal: orange color).

\section{DISCUSSION}

This study was performed to investigate two mechanical properties (Flexural strength \& modulus of elasticity) of two base materials (Activa Bioactive base and Ionoseal glass ionomer composite cement).

Liners are materials applied over dentin as a thin layer, aiming to seal the cavity floor and walls, promoting pulp protection from the influx of bacteria and irritants from restorative procedures. These materials can be used to fill large cavities, due to their rheological and mechanical properties such as low viscosity and elastic modulus. Those characteristics allow them to improve not only stress distribution over dentin during masticatory functions, but also the marginal integrity of composite restorations. Glass ionomers have been used as liners for more than 40 years, due to properties such as: thermal expansion coefficient similar to dentin; bacteriostatic action, fluoride release, low shrinkage, and the ability to bond to the tooth structure by calcium chelation. However, they present high sensitivity to humidity, low mechanical strength and wear resistance, and are unsuitable as a restorative material in areas of direct occlusal stress. Although some studies show that the use of a glass ionomer liner improves shrinkage stress distribution and decreases cuspal deflection in large cavities. ${ }^{6}$

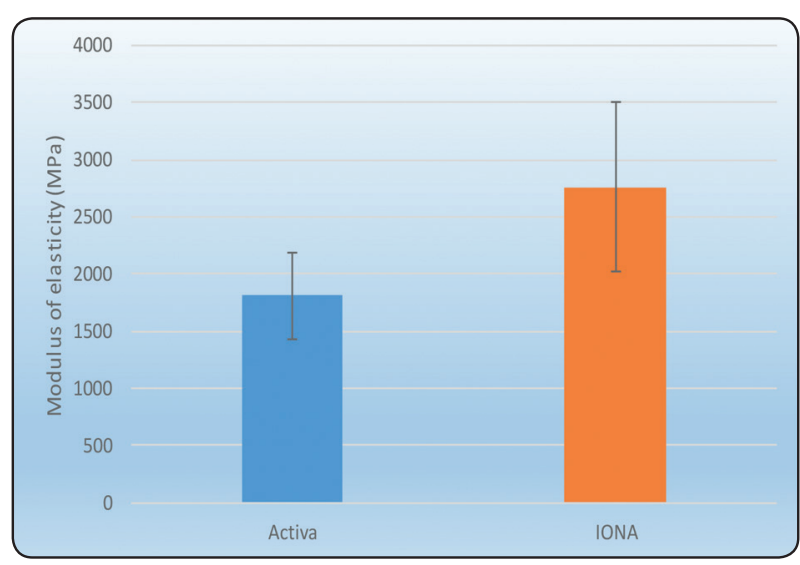

Fig. (2): Bar chart representing mean \& standard deviation values for modulus of elasticity values of the two materials. (Active: blue color \& Ionoseal: orange color).

ACTIVA BioACTIVE-BASE/LINER has all the advantages of glass ionomers in a strong, resilient resin matrix which will not chip or crumble. It forms chemical bond with tooth tissues, it seals against microleakage and it releases calcium, phosphate and fluoride. It is more durable and fracture resistant than resin composites, glass ionomers and RMGICs. ACTIVA is the first bioactive base/ liner with an ionic resin matrix, a shock-absorbing resin component and bioactive fillers that mimic the physical and chemical properties of natural teeth, it is more bioactive than glass ionomers. It releases and recharges with calcium, phosphate and fluoride ions. Finally ACTIVA contains no Bisphenol A or Bis GMA and no BPA derivatives.?

Ionoseal is considered a polyacid modified composite resin or compomer. It presented the highest bond strength values, whether associated with an adhesive system or not. It presents resinous acidic monomers similar to the ones found in self-adhesive resin cements that are used to form demineralization and bonding to tooth surface. These monomers are predominantly methacrylate monomers responsible for demineralizing dentin surface and promoting stable bonding with calcium, forming a stable salt. ${ }^{8}$

Under the international testing standard (ISO 
4049), three point flexural strength test is the primary strength test for resin containing restorative materials, so it was used in the current study to examine both resinous base materials used. Flexural strength is always investigated for dental materials as a common mechanical testing method, on the other hand mechanical fatigue testing can reveal additional important mechanical behavior that should be considered, therefore, flexural fatigue (modulus of elasticity) was investigated in addition to flexural strength for both materials (RMGICs), in order to evaluate their mechanical characteristics. Flexural strength and flexural fatigue were characterized and compared for both materials since they are considered useful in the characterization of base materials as stated by ISO 4049, which stated also that they are indicative of the material's ability to resist high masticatory forces without failure. ${ }^{5}$

Flexural strength values reported previously in literature for conventional RMGI materials ranged from 42 to $66 \mathrm{MPa} .{ }^{9}$ The mean flexural strength values for the two tested materials; Activa Bioactive RMGIs and Ionoseal were not statistically different in this study. Values were above the minimum requirement of ISO 4049. The relatively high mechanical properties of the dual-cured (Activa) of this study could be attributed to the effect of photopolymerization, since Novais et $\mathrm{al}^{10}$ stated that in order to provide optimal mechanical properties, initial self-cure conversion of double bonds is insufficient, and all dual-cured resin materials should receive photopolymerization to achieve superior conversion and optimum material properties.

Also increase of flexural properties of resin materials is directly proportional to the increase of the amount of inorganic filler by weight. Consequently, it can be expected that a composite resin with large amount of filler shows excellent mechanical properties as observed in this study. ${ }^{11}$ Activa Bioactive Restorative, will be suitable in higher stress bearing areas as it contains a proprietary, resilient resin matrix with energy-absorbing elastomeric components (a mixture of diurethane and methacrylates with modified polyacrylic acid \& polybutadiene modified diurethane dimethacrylate).

Particle size may influence the strength of glass ionomer materials, the smaller particle size results in greater surface volume for polymeric acid and glass interaction and lead to faster maturation. Also, the use of smaller particles increased the setting reaction, however may compromised the material strength. ${ }^{12}$

Curing of RMGIs can be done by an acid base chemical mechanism, by a thermal activated initiator, by a photochemical mechanism through the photo initiator activated by blue light, or simultaneously with both mechanisms. In a previous study the authors ${ }^{13}$ found that RMGI had significantly high biaxial flexure strength values, that increased the ability to undergo flexure without fracturing, and raised the overall strength, and the same findings occurred in this study.

RMGIs contain reactive, ion-releasing glasses, which render this class of materials "bioactive." Activa Bioactive materials release calcium, phosphate, and fluoride ions that interact with dentin and enamel and so benefit the longevity of these materials. Furthermore, the addition of energyabsorbing properties through using proprietary resins adds another benefit to Activa Bioactive materials making them more resilient against impact forces. Also being a RMGIs reduces their sensitivity to water loss compared to conventional GIs. ${ }^{14}$

For a luting cement material to provide reasonable deformation under loading, it's modulus of elasticity has to fall between those of dentin and restorative material, and since the modulus of dentin is between 12 and $20 \mathrm{GPa}$, so cements with higher modulus of elasticity are considered more desirable, as higher elastic modulus allows the cement to resist elastic deformation in areas of high biting forces. ${ }^{15}$ 
With regard to the modulus of elasticity, the nano particulate resin composite Ionoseal that is indicated as lining and to fissure sealing and restoration of smaller lesions, showed higher flexural modulus values than the other tested material (Activa).

The flexural strength test allows to obtain the results of the flexural modulus, also called modulus of elasticity, and the modulus of elasticity values (measured in the GPa) are directly proportional to the flexural resistance values (measured in $\mathrm{MPa}$ ). As increasing the amount of filler significantly improves all the mechanical properties of the material justifying our findings in which Ionoseal had higher modulus of elasticity values than those of Activa. ${ }^{16}$

The increase of the flexural properties of resin materials is directly proportional to the increase of the amount of inorganic filler by weight. Consequently, it can be expected that a composite resin with large amount of filler shows excellent mechanical properties as observed in this study. ${ }^{17}$

According to the International Standards Organization (ISO), the flexural strength is the mechanical resistance condition known as a failure caused by the tension of the resin material measured by its curvature. The clinical relevance of this property is present primarily in the act of mastication, when there are different masticatory forces, which induce various stresses, both in the tooth and the restoration. In addition to the flexural strength, another important parameter supplied by the mechanical flexural test is the modulus of elasticity, which describes the relative stiffness or hardness of a material measured by the reduction in the elastic region of the deformation/stress diagram. It is the principle of the lower deflection for a given value, the greater is the value of the modulus of elasticity. Its importance is because different clinical situations require a restorative material with different elastic moduli. ${ }^{11}$

\section{CONCLUSIONS}

Activa Bioactive-enhanced RMGIs demonstrated comparable flexural strength to Ionoseal glass ionomer composite cement. Flexural strength and fatigue properties of both materials achieved the ISO 4049 requirement for occlusal restorations.

\section{REFERENCES}

1. Khoroushi M, Keshani F. A review of glass-ionomers: From conventional glass-ionomer to bioactive glassionomer. Dent Res J (Isfahan). 2013;10(4):411-420.

2. ACTIVA $^{\mathrm{TM}}$ BioACTIVE-BASE_LINER ${ }^{\mathrm{TM}}$ Archives Pulpdent.

3. Khodadadi, Effat BE, Karimian N, Khafri S. Evaluation of microleakage of Ionoseal filling material as a fissure sealant agent. Casp J of Dent Res. 2014:39-45.

4. Bp D, Continental J, Hydrochloride D, Simone G, Tpo D. Safety data sheet Safety data sheet. Carbon N Y. 2005;1173(i):1-8.

5. Garcia-Godoy F, Morrow BR, Pameijer CH. Flexural Strength and Fatigue of New Activa RMGICs. J Dent Res. 2012;93:254

6. Zanatta RF, da Silva TJ, Huhtala MFRL, Borges AB, Torres CRG. Effect of self-etching dual-curing universal adhesive system application on bond strength of dentin resinous liners dentin. J Adhes Sci Technol. 2016;30(23):2557-2564.

7. ACTIVA ${ }^{\mathrm{TM}}$ Overview Archives - Pulpdent.

8. Ferracane JL, Stansbury JW BF. Self-adhesive resin cements - chemistry, properties and clinical considerations. J Oral Rehabil. 2011 Apr;38(4):295-314.

9. Pameijer CH. Flexural Strength and Flexural Fatigue Properties of Resin-Modified Glass Ionomers. 2015;(July).

10. Veridiana Resende NOVAIS, Luís Henrique Araújo RAPOSO, Rafael Resende de MIRANDA, Camila de Carvalho Almança LOPES, Paulo Cézar SIMAMOTO, JÚNIOR and Carlos José SOARES. Degree of conversion and bond strength of resin-cements to feldspathic ceramic using different curing modes. J Appl Oral Sci. 2017 JanFeb; 25(1): 61-68.

11. Massotti TG, Barcellos DC, Petrucelli N, Tribst JP, Gonçalves SE de P. Analysis of flexural strength of 
composite resins polymerized by 2 nd and 3 rd generation leds. Brazilian Dent Sci. 2015;18(1):67.

12. Nicholson SKS and JW. A Review of Glass-Ionomer Cements for Clinical Dentistry. J Funct Biomater. 2016 Sep; 7(3): 16.

13. Rueggeberg FA, Giannini M, Arrais CAG, Price RBT. CritiCal review Dental Materials/Dentistry Light curing in dentistry and clinical implications: a literature review. 2017;31:64-91.

14. Najeeb S, Khurshid Z, Zafar MS. Modifications in glass ionomer cements: Nano-sized fillers and bioactive nanoceramics. Int J Mol Sci. 2016;17(7).

15. Soares CJ, Faria-E-Silva AL, Rodrigues $M$ de $\mathbf{P}$.
Polymerization shrinkage stress of composite resins and resin cements - What do we need to know? Braz Oral Res. 2017;31:49-63.

16. Adalberto Rodrigues Junior Cesar Henrique Zanchi Rodrigo Varella de Carvalho Flávio Fernando Demarco Students S, - P, Fernando Demarco F, Junior RS. Flexural strength and modulus of elasticity of different types of resin-based composites Resistência à flexão e módulo de elasticidade de diferentes tipos de resina composta MSc Student. Braz Oral Res. 2007;2121(11):162116.

17. Choi KK, Ferracane JL, Ryu GJ, Choi SM, Lee MJ, Park SJ. Effects of cavity configuration on composite restoration. Oper Dent. 2004;29(4):462-469. 